\title{
Evaluation of the Types and Comprehensive Effects of Ecological Migration in China: Taking the Ecological Protection and Land Tenure Protection of Xihaigu Area in Ningxia as an Example
}

\author{
Yizhen $\mathrm{Xu}^{1}$ \\ ${ }^{1}$ Shanghai World Foreign Language Academy, Shanghai, China \\ Correspondence: Yizhen Xu. E-mail: jennifer_xu@aliyun.com
}

Received: August 10, 2021

Accepted: August 22, $2021 \quad$ Online Published: August 30, 2021

doi:10.5539/ass.v17n9p38

URL: https://doi.org/10.5539/ass.v17n9p38

\begin{abstract}
The ecological migration project in the Xihaigu Area of Ningxia, the first of such projects to be initiated with the longest history, is a typical example of China's ecological migration projects. Through the methods of field investigation, in-depth interviews, and examination of typical cases, the paper aims to evaluate Xihaigu's ecological migration project in the aspects of ecological restoration, poverty alleviation, income increase and social development. The conclusion is that China's ecological immigrants represented by Xihaigu's example have reached ecological improvement goals and economic and social development. At the same time, due to the government's vigorous promotion of this process, the fairness of the distribution of benefits for migrants in the earlier and later stages is slightly unbalanced, and the ecological protection awareness of the immigrants was always insufficient. The later process of immigration was relatively too fast, and ecological migration still faces further challenges.
\end{abstract}

Keywords: ecological migration, poverty alleviation and relocation, ecological restoration, social welfare

\section{Introduction}

\subsection{The Ecological Desolation of Xihaigu, Ningxia}

The environmental issues of Xihaigu, Ningxia, marked by soil salinization, ecological degradation and lack of freshwater, had deep climate, ecological and anthropogenic roots in its history. Aside from unreasonable human activity and population booms, Xihaigu, located in the Liupan Mountain Ranges bordering the Loess plateau, has an arid, fragile ecosystem. The region was deemed "unfit for human settlement" by the United Nations in 1972, suffering from environment-induced poverty. To change this situation and repair local ecology, ecological migration in Xihaigu started in its primary form in 1980 - the "Diaozhuang" mode of migration. It resettled residents of Xihaigu to the flatlands near Yinchuan city, where they reclaimed land that was more suitable for farming or sought opportunities in the city. This "Diaozhuang" mode later morphed into ecological migration policies starting from 2000. With the central government's support, eco-migration projects took place in ecologically fragile and impoverished regions in Ningxia, relocating 7 million people. After more than forty years of effort, the environment in Xihaigu has improved dramatically, along with remarkable poverty alleviation. Large-scale ecological migration has also brought about important research topics such as land ownership in ecological migration, ecological effect of migration, and evaluation of social improvement and poverty elimination.

Ecological migration in the case of Xihaigu is an example of "environmentally induced population movement." IOM, the International Organization for Migration, defines environmental migrants"persons or groups of persons who, predominantly for reasons of sudden or progressive change in the environment that adversely affects their lives or living conditions, are obliged to leave their habitual homes, or choose to do so, either temporarily or permanently, and who move either within their country or abroad" ("Discussion Note", 2007). China's ecological migrants are also one of more Chinese characteristics. In China, the general definition is:they are under "ecological migration" directed by the government to get rid of poverty and improve the ecological environment (Chen, 2009). While Western Society was concerned about environmental migration, Chinese scholars have also studied this issue. However, due to the difference in national conditions, Chinese scholars and Western scholars have taken different research focuses. While western scholars pay close attention to "climate refugees", climate 
change related migrants which belong to the category of environmental migration (Piguet, 2008), Chinese scholars have a strong interest in governmental action. There is extensive research on "ecological migration" under the leadership of CCP to alleviate poverty, get rich, and improve the environment. China's "ecological migration" involves "environmental migration." Some scholars have further subdivided the incentives, scale, and characteristics of environmental migration. Based on various classification schemes, environmental migration can be divided into environmental disaster migration, environmental degradation migration, and environmental expropriation migration (Chen, 2009). The "ecological migration" in this article belongs to the category of environmental degradation migration.

\subsection{Historical Changes and Trial Performances of the "Ecological Migration" Project}

Since 2001, with the vigorous support of the state, Ningxia has carried out four phases of large-scale ecological migration, which can be divided into the following stages (Shu et al., 2017):

1. The first stage: Relocation of migrants under the Poverty Alleviation Relocation pFrogram (2001-2007);

2. The second stage: In-county ecological migration in the central arid zone (2008-2012);

3. The third stage: "Twelfth Five-Year Plan" ecological migration in the central and southern regions (2011-2015).

4. The fourth stage: Relocation from mountain-top to mountain-bottom for the purpose of ecological restoration from 2015.

This article will compare the measures of the "Diaozhuang Mode" of migration, In-county Migration, and Cross-county Migration, and evaluate the ecological and social impact of migration policies in the Xihaigu region.

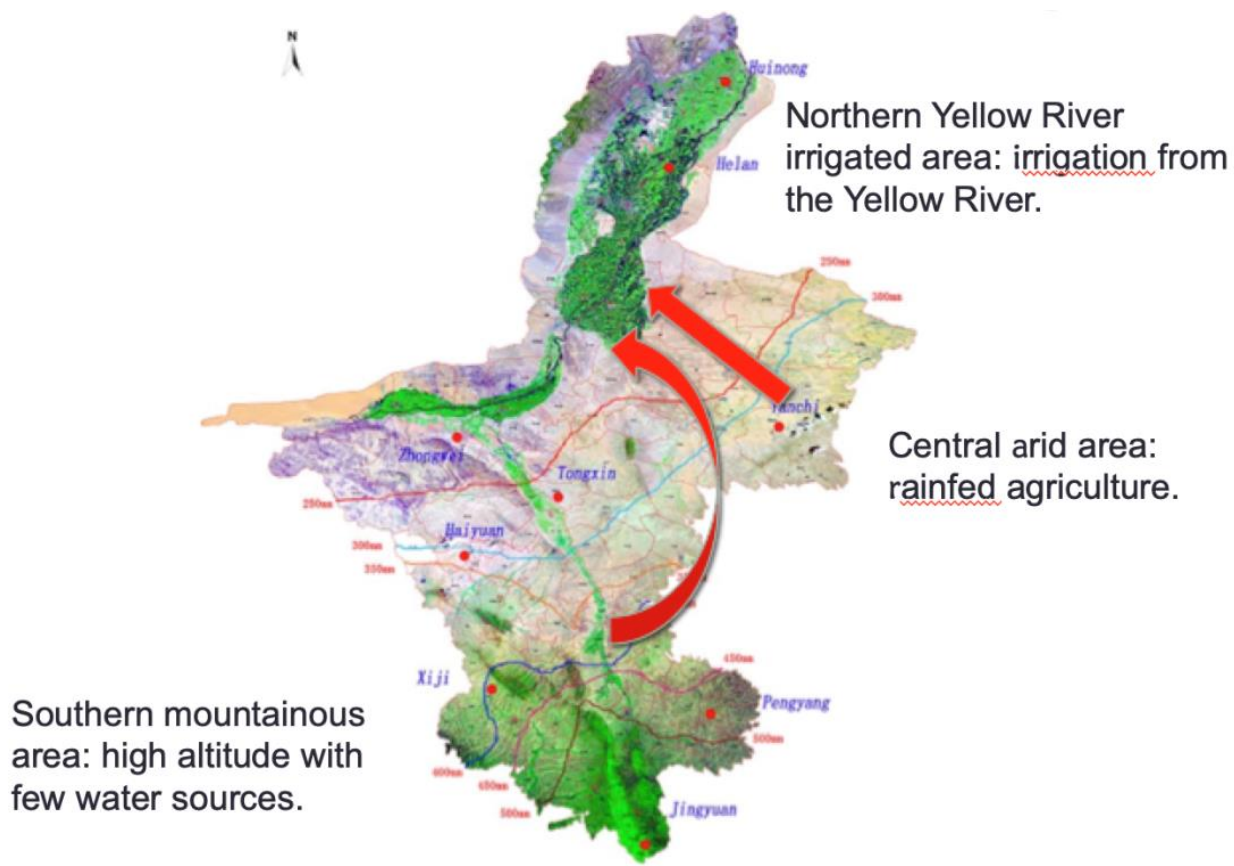

Figure 1. Three topographies in Ningxia and the routes of ecological migration (marked by red arrows)

\section{Methodology}

Our team's study interview ecological migrants and local officials based on field research involving in-depth interviews on different migration policies in the past forty years to collect information regarding their pre-migration and current living conditions and how migration policies affected their livelihoods. The sample size is 56 households from 9 villages located in 4 major counties of Xihaigu, and information obtained from interviews are later subject to qualitative analysis. Aside from interviewing those involved in ecological migration, the field research incorporated examinations of the current ecology in the core protection region of the Liupan Mountains.

Additional information on the historical and environmental background and policy implementation of ecological 
migration is obtained through evaluations of previous records and case studies in Xihaigu, along with analysis of laws and policies issued on ecological migration.

\section{Results and Discussion}

The Ecological migration project has seen remarkable progress in countering the anthropogenic decline of the environment, reducing poverty, and improving living standards sustainably. The United Nations proposed the 17 Sustainable Development Goals in 2015 to ensure worldwide peace and prosperity by 2030 (UNDP, 2015). Although the ecological migration of Xihaigu in 40 years still has many problems, those goals they are trying to get or have got include: "no poverty," "good health and well-being," "quality education," "decent work and economic growth," "sustainable cities and communities," "climate action," "Industry, Innovation and Infrastructure" and "life on land." and so on.

\subsection{Current Strengths of Ecological Migration Policies in Xihaigu}

\subsubsection{Ecological Recovery in Emigrated Regions}

The Liupan Mountain Area, where the majority of emigration took place in Xihaigu, have demonstrated major progress in ecological recovery in the course of migration. Up to the issuance of The 13th Five Year Plan in 2016, 153,400 hectares of ecologically degraded land has been restored (Government documents of Ningxia Autonomous Region, 2016). Measures to enhance ecological recovery after the relocation of residents in Xihaigu involve grassland restoration, reforestation, measures to prevent soil erosion and disposal of waste from shelters no longer inhabited after migration. Grasses are artificially grown and seeded in barren areas once used for farming and housing to fasten soil and reestablish natural flora. At the Jing River source located in the core zone of ecological recovery, Infrastructure to stabilize gully heads, check dams and sediment storage dams are established or strengthened to reduce nutrition loss in soil erosion.

As the Liupan Mountain Ranges in Xihaigu originally consisted of forest ecosystems, reforestation after ecological migration is a crucial advancement in the process of ecological recovery. Trees have been grown for the purpose of maintaining a mild microclimate to sustain the river source, reduce soil erosion and combat desertification. The current strategy employed is artificial heterogeneous planting of drought-resistant trees including Northern Asian species of pine, spruce, birch and platycladus as well as shrub species including seabuckthorn, cloves, jaundia, and lime thorns. Field research and interviews reveal that the current recovery of local flora has increased the shade and humidity as well as the return of wild animals including boars and hares.

During the "Diaozhuang Mode" early stages of migration, migrants were resettled on the outskirts of Yinchuan, where they reclaimed uninhabited land close to the Yellow River, which are more suitable for farming. In the process, they are allowed to retain their original farmlands and shelters in Xihaigu, making it difficult to push forward ecological recovery. In more recent years, with the more rapid progress of moving and resettling residents from Xihaigu and claiming the land in the emigrated area to reestablish wildlife habitats, as well as systematic regulations to prevent lumbering and poaching, ecological recovery has been prompted forward at a rapid pace.

The compatibility of population and ecological carrying capacity is key to the issue. From a geographical perspective, the Liupan Mountain in the Xihaigu Region is an essential ecological water conservation area. Unfortunately, this relatively fragile water conservation site has been severely mutilated due to the introduction of a large population in the Ming and Qing dynasties. That resulted in severe soil erosion and drought in the area. In the last century, the UN Food Development Agency listed this impoverished and arid area as "one of the least suitable areas for human habitation". However, if the population becomes more compatible with the ecological carrying capacity, the ecological function of Xihangu could be restored within a decade.

Therefore, the government's legal policy is scientifically based on the earth's ecological patterns. The ecological migration project, along with ecological restoration through returning farmland to forests reversed the trend of ecological deterioration and, at the same time, effectively reduced the ecological burden caused by the population size. This ensures the ecological restoration and sustainable development of the Xihaigu Region in Ningxia. It is very reasonable on the aspect of protecting Xihaigu's ecological functions, as humans ought not to permanently exploit natural resources for granted.

There are many cases of such ecological immigration conducted by the Chinese government in ecologically fragile zones. When local population exceeds the load of the ecological environment, such large-scale government-directed immigration and social intervention is necessary. Of course, there must also be a detailed plan to protect the human rights of affected migrants in cultural, economic, and social aspects. 


\subsubsection{Poverty Alleviation Progress as a Result of Ecological Migration}

In forty years, poverty alleviation has undergone significant progress in the Xihaigu region through ecological migration. In total, more than one million impoverished residents of ecologically damaged areas in Xihagu have been relocated through the migration project. Methods to alleviate people out of poverty after relocation include supporting impoverished communities with industries and technology according to the local agricultural productions and natural conditions, such as the establishment of grape plantations and a wine factory in the Zhenbeipu resettlement villages and industry clusters such as that of Xinjing Town. They provide job opportunities for the farming population, who used to work on farmland in the Liupan Mountains that yielded little crops.

Aside from industries, the government's poverty alleviation policies are also in place to reduce and eliminate poverty among ecological migrants, from early attempts of subsidies in the 1980s to targeted poverty alleviation through detailed poverty registration and raised housing standards and subsidies for the needy situations.

China's decades-long ecological migration project is also known as the "Poverty Alleviation Relocation Project." Although the ecological degradation of the Xihaigu area in China is the fundamental reason for poverty and unsustainable development, propaganda focused on migration for poverty alleviation is more widely accepted by locals in implementing the ecological migration policy. Therefore, these two project names have been cross-used in the ecological migration of the Xihaigu area in Ningxia in recent decades. Ecological restoration is the essential reason for migration, and poverty alleviation is the social effect that follows.

In the process of relocation and resettlement, China has coordinated and promoted the follow-up development of relocated households in poverty. The policy was to ensure that every relocated household are out of poverty. Among the impoverished people planned to be relocated, poverty alleviation is arranged through the development of industries such as farming, animal husbandry and secondary industry; Poverty alleviation is also achieved through resettlement methods such as employment, self-employment, and public welfare positions. Other methods include asset income support and aid from social security (National Development and Reform Commission, 2016). The government takes the lead in relocating residents. They were initially an agricultural population, and the farmlands they own after relocation are often not as large as their original land in the mountainous area. The earliest ecological immigrants we interviewed were allocated $15 \mathrm{mu}$ (2.5 acres) of land per household in the suburbs of Yinchuan, which was a substantial area of land, although many immigrants still need to reclaim the barren land they obtained first before they can own it as farmland. However, as the land resources in Ningxia Province become increasingly scarce, immigrants who moved from the mountains in the past two years have only received less than $1 \mathrm{mu}(0.165$ acres $)$ of land for each household, making the non-agriculturalization of the agricultural population a major concern.

Therefore, another major challenge the government faces in ecological migration is to enable the population of traditional agriculture and animal husbandry to convert to occupations conducive to ecological restoration and reconstruction. For example, part of the agricultural population has turned to forest conservation and tree nursery industries to promote returning farmland to forests. Free-range livestock must be raised in captivity, so some were engaged in feed planting and processing industries. There are also some high-value-added agricultural industries that use rural land for special economic crop cultivation, greenhouse vegetable cultivation, wine making, and wolfberry production. Of course, due to the reduction of agricultural land and the increase of ecologically conserved zones, more former agricultural populations must participate in industrial production and gradually convert into non-agricultural populations.

\subsubsection{Social Development in Resettled Communities}

Comprehensive social development among migrant communities for the better include overall improved living standards and better education healthcare. Access to clean water and convenience of transportation are among the notable improvements in the living standards of migrants from Xihaigu. In all of the resettlements covered in this field research, facilities including power and tap water are currently available. According to data in $2020,90 \%$ of the homes of ecological migrants were built after 2009 in certain resettlements (Liu \& Chen, 2014). The migrants' locations mainly follow the principles of being "alongside rivers, roads, and cables." the new settlements are all near asphalt driveways and some have complete systems of public transportation.

Resettlement communities in ecological migration are equipped with convenient facilities and social welfare for the needy. The town Xingjing, a resettlement site first established in 1983, now has urbanized facilities, including bus systems free for the elderly, collective waste classification and disposal sites and education centers. Resettlement villages all have village clinics, and additional healthcare needs are more accessible due to transportation convenience. The migrants of Xihaigu are subject to a much more urbanized, sustainable lifestyle 
compared to the conditions before migration. Migrants also have better education opportunities, with school drop-out rates due to poverty currently zero.

\subsection{Statistics and Data Analysis}

\subsubsection{Legacy Issues Regarding the Fairness of Different Stages Of Migration}

The ecological migration in Xihaigu is a long-term project consisting of different policies issued according to changing situations, resulting in legacy issues regarding the fairness of subsidies, land ownership, and opportunities in settlements for migrants that moved out at different periods. Those who emigrated at the start of the "Diaozhuang Mode" migration had an abundance of uninhabited land near Yinchuan's city during an age of rapid development in Western China. They have significantly larger land areas in convenient positions closer to cities. An interviewee whose family moved out in the 1980s has land management rights over 1 hectare of farmland. However, compared to earlier migrants, those who moved out during the in-county and cross-county ecological migration after 2000 often have management rights over much smaller areas, less than 0.06 hectares in some cases of in-county migration. The later migrants also have less opportunity to live closer to urbanized areas. The disparity is a result of a lack of available land for further resettlement. Migration policies after 2000, especially those during the 12th (2011-2015) and 13th Five Year Plan (2016-2020), are also less lenient compared to former ones. The handing over of management and contract rights for the migrants' former farmland and homesteads in the Liupan Mountains has become compulsory for ecological restoration. While the "Diaozhuang Mode" was slow and not effective enough in pushing forward ecological reparation, the more recent regulations may be overly progressive and less humanized.

\subsubsection{Lack of Information Disclosure and Public Participation}

A problem widely observed during interviews with ecological migrants of all the locations sampled is that they lack knowledge and consciousness over the concept of ecological degeneration and protection. When interviewed about their understanding of the significance of ecological migration, answers frequently given by migrants include poverty alleviation, education, improved living standards, and convenient transportation. However, they know little about the task of ecological restoration in the areas from which they moved out. This phenomenon has roots in the traditional mindsets of agriculture-based society and the lack of information disclosure. Government propaganda often stressed the goal of poverty alleviation but not ecological restoration, for example migrating under the title of "poverty alleviation relocation" in the 13th Five Year Plan. The lack of information causes residents' unknowing of ecological implications of migration in Xihaigu, leading to insufficient public participation over migration and long-term environmental protection.

\subsubsection{Long-term Risk Factors of the Environment}

While widespread improvement in the ecological state of Xihaigu has demonstrated the positive impacts of ecological migration, the long-term maintenance of a stable ecological condition remains in question. There have been increased sightings of herbivores, including wild boars and hares, but not indigenous predators such as wolves. Large herbivores such as wild boars feed on and trample local vegetation, causing difficulties and potential danger for the artificial restoration of trees and small settlements in the Liupan Mountains still undergoing migration. The reestablished ecosystem may still be vulnerable to future devastation and possible conflict between wildlife and residents near reserved areas of Xihaigu may occur later on.

As the source of the river Jing, a large branch of the Yellow River that flows through northwestern provinces including Ningxia, Gansu, and Shanxi, the climate in Xihaigu is crucial for trans-provincial freshwater supplies. Therefore, in the long term, trans-provincial ecological compensation policies can be implemented to ensure collaborative and win-win effort between provinces, providing economic support to sustain the ecological migration and environmental recovery efforts in Xihaigu.

There is also a need for further education for Xihaigu migrants to push forward poverty alleviation after migration. Many resettled households demonstrate a high reliance on governmental subsidies and poverty alleviation policies, refusing to seek alternative livelihoods independently after migration.

\section{Conclusion}

As China's earliest eco-migration project taking place in the poorest and most ecologically damaged region, the government-led ecological migration and poverty alleviation projects in Xihaigu are generally suitable. Long-term ecological migration policies, which spans twenty or thirty years before and after, can indeed be carried out in Ningxia Autonomous Region to balance ecological protection and poverty reduction, and eventually to achieve the sustainable development goals of the United Nations. Some of the more radical and rapid ecological migration in the later period, however, was not as appropriate as the earlier ones, which repaired 
the ecology while taking into account economic, cultural and ethnic factors.

\section{References}

Brown, O. (2007). Climate change and forced migration: Observations, projections and implications (No. HDOCPA-2007-17). Human Development Report Office (HDRO), United Nations Development Programme (UNDP).

(n. d.). Discussion Note: Migration and the Environment. International Organization for Migration. Retrieved January 15, 2021, from https://www.iom.int/sites/default/files/jahia/webdav/shared/shared/mainsite/about_ iom/en/council/94/MC_INF_288.pdf

Government documents of Ningxia Autonomous Region. (2016). Relocation plan for poverty alleviation in Ningxia during the 13th five year plan (NZF [2016] No. 66). Retrieved August 2, 2021, from http://www.nx.gov.cn/zwgk/qzfwj/201910/t20191023_1811301.html

Liu, T., \& Chen, X. (2020). Relocation for Poverty Alleviation: Effect, Problems and Policy Reflections: Based on a Survey in S Village, H County, Ningxia Province. Xinjiang State Farms Economy, 10, 15-23. https://doi.org/10.3969/j.issn.1000-7652.2020.10.002

Zhou, N. (Ed.). (2016). The National Relocation Project for Poverty Alleviation and Relocation is Progressing Smoothly. National Development and Reform Commission. Retrieved from http://www.gov.cn/xinwen/2016-12/15/content_5148516.htm

Piguet, E. (2008). Climate Change and Forced Migration [Review of Climate Change and Forced Migration]. Journal of Humanitarian Aid, 153.

Shu, X., Nie, J., \& Fan, Y. (2017). Change of Livelihood Mode and Diversified Development of Ecological Immigrants in Ningxia From the Perspective of Targeted Poverty Alleviation. Social Sciences in Ningxia, 5, 147-154. https://doi.org/10.3969/j.issn.1002-0292.2017.05.023

UNDP. (2015). Sustainable Development Goals | UNDP. UNDP. Retrieved from https://www.undp.org/sustainable-development-goals

Yong, C. (2009). Some Perspectives on Several Basic Issues in Studies of Environmental Migration. China $\begin{array}{lllll}\text { Population, } & \text { Resources }\end{array}$ https://doi.org/10.3969/j.issn.1002-2104.2009.05.013

\section{Copyrights}

Copyright for this article is retained by the author(s), with first publication rights granted to the journal.

This is an open-access article distributed under the terms and conditions of the Creative Commons Attribution license (http://creativecommons.org/licenses/by/4.0/). 